OPEN ACCESS

Edited by:

Chun Hung Chu,

The University of Hong Kong, Hong Kong, SAR China

Reviewed by:

Sezen Köse,

Ege University, Turkey

Thomas Gerhard Wolf,

University of Bern, Switzerland

*Correspondence: Jung-Wei Chen jwchen@llu.edu

Specialty section: This article was submitted to

Preventive Dentistry, a section of the journal

Frontiers in Oral Health

Received: 12 March 2021

Accepted: 21 June 2021

Published: 17 August 2021

Citation:

Tran J, Chen J-W, Trapp L and McCormack L (2021) An Investigation of the Long and Short Term Behavioral

Effects of General Anesthesia on Pediatric Dental Patients With Autism.

Front. Oral. Health 2:679946. doi: 10.3389/froh.2021.679946

\section{An Investigation of the Long and Short Term Behavioral Effects of General Anesthesia on Pediatric Dental Patients With Autism}

\author{
Janine Tran ${ }^{1}$, Jung-Wei Chen ${ }^{2 *}$, Larry Trapp ${ }^{3}$ and Laura McCormack ${ }^{4}$ \\ ${ }^{1}$ Dental Resident, Pediatric Dentistry, Loma Linda, CA, United States, ${ }^{2}$ Pediatric Dentistry, Loma Linda, CA, United States, \\ ${ }^{3}$ Dental Anesthesiologist, Loma Linda, CA, United States, ${ }^{4}$ Private Practice Dentist, Pediatric Dentistry, Irvine, CA, \\ United States
}

Purpose: The purpose of this study was to compare the incidence of short and long term adverse behavioral effects of general anesthesia (GA) in healthy vs. moderate to severe autistic (ASD) children.

Methods: Forty healthy and 37 ASD children, aged 3-17 years, undergoing GA for dental surgery participated in this study. Their anesthesia records were reviewed, and their parents answered telephone surveys to assess activity level, sleep disturbances, gastrointestinal disturbances, central nervous system effects, and respiratory depression. Three follow-up surveys were taken $8 \mathrm{~h}, 24 \mathrm{~h}$, and 3 months post-surgery.

Results: Four hundred fifty-five incidences of adverse behavioral effects occurred within $8 \mathrm{~h}$ post-surgery. Significantly more ASD patients had difficulty walking $(P=0.016)$ and nausea $(P=0.030)$, while more healthy children snored in the car ride home $(P=0.036)$ and talked about the dental surgery $(P=0.027)$. Three months post-discharge, sixASD patients acted in a way that concerned caregivers compared to 0 healthy patients, $(P=0.008)$. Incidence of adverse behavioral effects significantly decreased from 8 to $24 \mathrm{~h}$ overall.

Conclusions: Most behavioral effects occur within $8 \mathrm{~h}$ post-surgery. There are potential long term adverse behavioral effects in ASD children from GA, but the chance is low and generally not long lasting.

Keywords: autism (ASD), general anesthesia, behavior effect, long term follow up, short term follow-up

\section{INTRODUCTION}

Behavior guidance is an essential component of pediatric dentistry. When necessary, oral sedation is advised. When basic behavior guidance techniques and oral sedation are inadequate to achieve patient cooperation for treatment, general anesthesia (GA) becomes the main option. Very young or medically compromised patients require dental procedures performed under GA when they need more complicated or extensive treatment. There is ample research on the behavioral effects of oral sedation in healthy pediatric patients, but very few studies on the behavioral effects of GA.

McCormack et al. reported that most adverse behavioral events occurred within the first $8 \mathrm{~h}$ of discharge after oral sedation [1]. Ritwik et al. reported similar adverse effects $8 \mathrm{~h}$, even up to $24 \mathrm{~h}$ after oral sedation [2]. These patients experienced irritability, vomiting, and increased sleep [2]. These studies could be applied to explore the behavioral effects of GA. 
There are case reports, however, on behavioral changes in patients with autism spectrum disorder (ASD) after treatment under GA [3]. Matton et al. reported two patients born with ASD and attention deficit hyperactive disorder (ADHD) after undergoing GA for oral surgery [3]. The reported postoperative behavioral changes included irritability, reduced social engagement, loss of appetite, insomnia, and daytime somnolence [3]. Becker et al. concluded that $10-20 \%$ of hospitalized patients experience adverse anesthetic drug reactions [4]. As these are only case reports, a prospective cohort study would provide valuable insight into the behavioral effects of GA in this population of patients.

Many animal studies suggest that there is an association between early exposure to GA and long-term impairment of the developing cognition. Learning, memory, motor function, and attention could be affected [5-7]. Rodents and nonhuman primates exposed to anesthesia were found to experience apoptosis of neuronal cells, specifically in the cerebral cortex [8-12]. These studies tested the effects of ketamine, propofol, and isoflurane [3]. These anesthetics are N-methyl-D-aspartate glutamate receptor antagonists and GABA agonists, which may cause neurodegeneration in the cortical regions of the brain and may ultimately lead to disorders like ADHD and ASD [7].

There is an increasing concern regarding the potential effects of GA surgery in children. SmartTots is a partnership between the International Anesthesia Research Society and the Food and Drug Administration that funds clinical studies on the cognitive development in children exposed to GA at an early age [10, 13, 14]. Pediatric Anesthesia Neurodevelopment Assessment is a multicenter study that investigates the neurodevelopment in children who have undergone GA [15].

Existing research on the effects of GA on child behavior and cognitive development have inconclusive results. Behavioral regression was worse when the patient had pre-operative anxiety, was in pain, or had not eaten [3]. Camm et al. found that children who had dental treatment under GA were reported to have significantly more stress [16]. In addition, a study by Bakri et al. [5] concluded that children with at least two GA surgeries were at increased risk of developing anxiety, depression, ADHD, and sleep problems, but no increased risk for developing withdrawn or aggressive behaviors, fatigue, and pain.

The purpose of this study is to compare the incidence of short and long term adverse behavioral effects of GA in healthy vs. moderate to severe autistic children. Any changes in behavior will be assessed at the time of GA administration as well as $8 \mathrm{~h}, 24 \mathrm{~h}$, and 3 months after discharge.

\section{METHODS}

The Loma Linda University (LLU) Institutional Review Board (IRB \#5180244) approved this prospective study to recruit participants from the Koppel Special Care Dentistry (SCD) Surgery Center. Informed consent was obtained from the patients' legal guardian at the pre-operative exam. A total of 77 patients aged 3-17 years were selected for this study, with no restrictions on gender, race, or ethnicity. These patients have been referred for complete oral dental rehabilitation under GA due to uncooperative behavior that rendered them unable to undergo any dental treatment in a clinical setting. Also included were patients in whom oral sedation was or believed to be ineffective and referred to the SCD center. Group 1 included 40 healthy children to serve as the control group. Group 2 consisted of 37 patients with moderate to severe autism, with no other existing medical conditions. The patients in this group were levels 2 and 3 severity of the autism spectrum disorder, as defined by the Diagnostic and Statistical Manual of Mental Disorders [17]. Level two severity ("requiring substantial support") is characterized by evident deficiencies in nonverbal and verbal communication skills, social impairments even with support, limited initiation of social interaction, diminished or abnormal responses, inflexible behavior, repetitive behaviors, and difficulty coping with change [1]. Level three severity ("requiring very substantial support") includes the same criteria as Level two but more severe; the characteristics of a Level 3 autistic patient contributes to lowfunctioning behavior [17].

The standard procedure for dental surgery under GA was followed according to the protocol at the SCD surgery center as well as the American Dental Association (ADA) and American Academy of Pediatric Dentistry (AAPD) Guidelines. General anesthetics used were Ketamine via intramuscular injection or Sevoflurane via inhalation for induction and Propofol via intravenous (IV) delivery for maintenance. Other adjuvant agents may be provided as necessary, including opiates and nonsteroidal anti-inflammatory drugs. Patients were continuously monitored, and their vital signs assessed with a precordial stethoscope, pulse oximeter, end tidal carbon dioxide, and electrocardiogram. Airway management was maintained by either intubated or non-intubated techniques. A treatment plan was created and reviewed with the legal guardian; subsequently, any and all necessary dental treatment was performed. Two percent lidocaine with 1:100,000 epinephrine was used as needed for local anesthesia, not to exceed $4 \mathrm{mg} / \mathrm{kg}$ lidocaine. When dental surgery was complete, patients were monitored in a recovery room, as defined by the ADA and AAPD Guidelines prior to discharge. These guidelines include continuous monitoring of vital signs, protective reflexes intact, the patient is able to talk and sit unaided if age appropriate, adequate hydration, and stable cardiovascular function and airway patency $[18,19]$. Post-operative care instructions were given to the patients' legal guardian before discharge.

The investigator and research assistant interviewed the parents, using a script to reduce bias in the presentation of the survey questions. The research assistant was calibrated to provide the survey. A Spanish translator was hired to obtain informed consent and provide survey questions when needed. On the day of surgery, an initial survey was completed, including questions regarding patient behavior before and after surgery. Patient anesthesia records were used to answer questions regarding events during surgery. Telephone surveys were given to the patients' legal guardian $8 \mathrm{~h}, 24 \mathrm{~h}$, and 3 months postdischarge. These time periods were selected based on previous studies which showed adverse behavioral events occurring within the first $8 \mathrm{~h}$ of discharge, even up to $24 \mathrm{~h}$ after oral 
sedation [1,2]. Questions in the survey aimed to assess any changes (defined as adverse behavioral effects) in the patients' activity level, sleeping habits, gastrointestinal (GI) system, central nervous system (CNS), and respiratory depression. Paradoxical reactions were also measured by questions related to abnormally aggressive behavior, crying or screaming inconsolably, being hyperactive, and biting or scratching. Responses were either "yes" or "no," and legal guardians were asked to explain any "yes" responses.

All responses were entered into Microsoft Excel 2016 (Microsoft, Inc., Redmond, Wash., USA) for data analysis. SPSS
Statistics software, version 25 (IBM, Armonk, N.Y., USA) was used to obtain descriptive and inferential statistics to analyze the collected data. A Chi-squared test was used to determine if there was a significant difference in incidence of behavioral effects between the two groups and between the different time points when the surveys were taken. The $t$-test was used to evaluate the amount of drugs used during surgery and to evaluate the combined adverse effects compared between the two groups. A Pearson correlation analysis was performed to determine any association between age, gender, BMI, drug used during surgery, and combined adverse effects.

TABLE 1 | Demographic data summary.

\begin{tabular}{|c|c|c|c|c|c|c|c|}
\hline Group & $\begin{array}{l}\text { Male } \\
N(\%)\end{array}$ & $\begin{array}{l}\text { Female } \\
N(\%)\end{array}$ & Mean age (years) & Mean BMI & $\begin{array}{l}\text { Mean surgery } \\
\text { time (min) }\end{array}$ & $\begin{array}{l}\text { Mean } \\
\text { recovery time } \\
\text { (min) }\end{array}$ & $\begin{array}{c}\text { Mean } \\
\text { xylocaine } \\
\text { amount }(\mathrm{mL})\end{array}$ \\
\hline \multicolumn{8}{|l|}{ Demographics } \\
\hline Healthy & $20(50.0)$ & $20(50.0)$ & $4.5 \pm 0.9$ & $16.1 \pm 1.4$ & $68.4 \pm 21.0$ & $35.6 \pm 16.0$ & $1.3 \pm 0.7$ \\
\hline ASD & $31(83.8)$ & $6(16.2)$ & $9.0 \pm 3.9$ & $19.8 \pm 4.67$ & $58.1 \pm 24.7$ & $41.4 \pm 15.7$ & $0.8 \pm 0.8$ \\
\hline Total & $51(66.2)$ & $26(33.8)$ & $6.7 \pm 3.5$ & $17.9 \pm 3.8$ & $63.4 \pm 23.3$ & $38.4 \pm 16.0$ & $1.0 \pm 0.7$ \\
\hline Group & $\begin{array}{l}\text { NKDA } \\
N(\%)\end{array}$ & $\begin{array}{c}\text { Antibiotic } \\
\qquad(\%)\end{array}$ & $\begin{array}{c}\text { Seasonal } \\
N(\%)\end{array}$ & $\begin{array}{l}\text { Multiple } \\
\text { N (\%) }\end{array}$ & $\begin{array}{l}\text { Other } \\
N(\%)\end{array}$ & & \\
\hline \multicolumn{8}{|l|}{ Allergies } \\
\hline Healthy & $30(75.0)$ & $1(2.5)$ & 5 (12.5) & $2(5.0)$ & $2(5.0)$ & & \\
\hline ASD & $26(70.3)$ & $3(8.1)$ & $6(43.2)$ & $1(2.7)$ & $1(2.7)$ & & \\
\hline Total & $56(72.7)$ & $4(5.2)$ & $11(14.3)$ & $3(3.9)$ & 3 (3.9) & & \\
\hline Group & $\begin{array}{l}\text { None } \\
N(\%)\end{array}$ & $\begin{array}{c}\text { Albuterol } \\
\boldsymbol{N}(\%)\end{array}$ & $\begin{array}{c}\text { OTC allergy } \\
N(\%)\end{array}$ & $\begin{array}{l}\text { Multi-vitamins } \\
\qquad N(\%)\end{array}$ & $\begin{array}{c}\text { Melatonin } \\
\qquad(\%)\end{array}$ & $\begin{array}{l}\text { Valproic } \\
N(\%)\end{array}$ & $\begin{array}{l}\text { Multiple } \\
\text { N (\%) }\end{array}$ \\
\hline \multicolumn{8}{|l|}{ Medications } \\
\hline Healthy & $23(57.5)$ & $5(12.5)$ & $4(10.0)$ & 7 (17.5) & $0(0)$ & $0(0)$ & $1(2.5)$ \\
\hline ASD & $13(35.1)$ & $1(2.7)$ & $3(8.1)$ & $2(5.4)$ & $2(5.4)$ & $1(2.7)$ & $13(35.1)$ \\
\hline Total & $36(46.8)$ & $6(7.8)$ & $7(9.1)$ & $9(11.7)$ & $2(2.6)$ & $1(1.3)$ & 14 (18.2) \\
\hline Drug & $\begin{array}{c}\text { Healthy } \\
\text { number (\%) }\end{array}$ & $\begin{array}{c}\text { ASD } \\
\text { number (\%) }\end{array}$ & $\begin{array}{c}\text { Dose for Healthy } \\
\text { (mean } \pm \text { SD } \\
\text { mg/kg) }\end{array}$ & $\begin{array}{c}\text { Dose for ASD } \\
\text { (mean } \pm \text { SD } \\
\text { mg/kg) }\end{array}$ & $P$-value & & \\
\hline \multicolumn{8}{|c|}{ Drugs used during surgery } \\
\hline Propofol & $40(100.0)$ & $37(100.0)$ & $9.3 \pm 7.8$ & $7.6 \pm 5.0$ & 0.243 & & \\
\hline Ketamine & $14(35.0)$ & $27(73.0)$ & $2.2 \pm 1.4$ & $2.7 \pm 1.4$ & 0.275 & & \\
\hline Ketorolac & $39(97.5)$ & $33(89.2)$ & $0.5 \pm 0.1$ & $0.5 \pm 0.3$ & 0.777 & & \\
\hline Zofran & 38 (95.0) & 31 (83.8) & $0.4 \pm 1.6$ & $0.1 \pm 0.2$ & 0.430 & & \\
\hline Demerol & $32(80.0)$ & $23(62.2)$ & $1.6 \pm 0.6$ & $1.0 \pm 0.5$ & $0.001^{*}$ & & \\
\hline Alfentanil & $21(52.5)$ & $16(43.2)$ & $40.9 \pm 18.0$ & $29.3 \pm 16.0$ & 0.050 & & \\
\hline Decadron & $27(67.5)$ & $27(73.0)$ & $0.4 \pm 0.7$ & $0.2 \pm 0.1$ & 0.089 & & \\
\hline Versed & $6(15.0)$ & $22(59.5)$ & $0.1 \pm 0.01$ & $0.04 \pm 0.01$ & $0.021^{\star}$ & & \\
\hline Succinylcholine & $2(5.0)$ & $4(10.8)$ & $0.5 \pm 0.1$ & $0.4 \pm 0.2$ & 0.840 & & \\
\hline Atropine & 4 (10.0) & $1(2.7)$ & $0.01 \pm 0.0$ & 0.004 (no sd) & $\mathrm{N} / \mathrm{A}$ & & \\
\hline Remifentanil & $1(2.5)$ & $3(8.1)$ & 32.2 (no sd) & $4.0 \pm 0.9$ & $0.001^{*}$ & & \\
\hline Benadryl & $4(10.0)$ & $8(21.6)$ & $0.7 \pm 0.1$ & $0.5 \pm 0.2$ & 0.164 & & \\
\hline
\end{tabular}

${ }^{\star} P<0.05$ using t-test to indicate difference in average dose of each drug used between Healthy and ASD groups. Bold values mean they are statistically significant. 


\section{RESULTS}

A total of 77 patients participated in this study, and the demographics data is summarized in Table 1. Fifty-seven patients (74\%) received mask induction with Sevoflurane, while 20 (26\%) received intramuscular induction with Ketamine. ASD patients had significantly more males, $(P=0.002)$, took more medications $(P<0.001)$, higher BMI $(P<0.001)$, and received intramuscular ketamine induction $(P<0.001)$. This group received significantly less lidocaine during procedure $(P=0.01)$. There was no significant difference between the two groups for post-surgical recovery time $(P=0.117)$. The more common drugs used during GA were Ketamine, Propofol, Ketorolac, Zofran, Demerol, Alfentanil, Decadron, Versed, Succinylcholine, Atropine, Remifentanil, and Benadryl. The healthy group received significantly higher dosages of Demerol $(P=0.001)$, Versed $(P=0.021)$, and Remifentanil $(P=0.001)$ (Table 1).

Overall, there were 77 survey questions and 5,929 responses, out of which $700(11.8 \%)$ were "Yes" responses that indicated an incidence of an adverse behavioral effect (Table 2). Survey 1 had 15 questions, 1,155 total responses, and 5 (0.043\%) "Yes" responses to show adverse effect during GA surgery. Survey 2 had 29 questions, 2,233 responses, and 455 (20.38\%) "Yes" responses. Survey 3 had 27 questions, 2,079 responses, and 194 (9.33\%) "Yes" responses. Survey 4 had 6 questions, 462 responses, and 46 (9.96\%) "Yes" responses.

At pre-op survey 1 (Figure 1), there were significant differences in behavior prior to GA induction. Significantly more ASD patients exhibited aggressive behavior $(P=0.004)$. Significantly more healthy patients spoke age-appropriately prior to GA induction $(P<0.001)$ and at discharge $(P<0.001)$. At $8 \mathrm{~h}$ post-discharge, significantly more healthy patients normally slept in the $\operatorname{car}(P<0.001)$, snored on the car ride home $(P=0.036)$, and talked about the dental surgery $(P=0.027)$. Significantly more ASD patients had difficulty walking $(P=0.016)$ and complained of nausea $(P=0.030)$ at this time period (Table 2). At $24 \mathrm{~h}$ post-discharge, significantly more healthy patients talked about the dental surgery $(P=0.048)$. At 3 months post-surgery (Figure 2), significantly more ASD patients acted in a way that concerned their parent/caregiver $(P=0.008)$. According to the Fisher's exact test, there was significantly more hyperactivity in the ASD group $(P=0.05)$ during this time. For the remaining survey questions, there were no significant differences between the two groups.

Questions were grouped together to compare types of adverse behavioral effects between the healthy and ASD groups (Table 2). There was no significant difference in the occurrence of an adverse reaction during surgery $(P=0.143)$. Comparing preoperative behavior, significantly more ASD patients showed aggressive behavior and cried inconsolably $(P=0.008)$ and did not speak appropriately for their age $(P<0.001)$. There was no significant difference in incidence of paradoxical reactions at $8 \mathrm{~h}$ after $(P=0.174)$ and $24 \mathrm{~h}$ after $(P=0.189)$. Using Fisher's exact test, the ASD group had significantly more paradoxical reactions $(P=0.05)$, reported as more hyperactivity, at 3 months postsurgery. Significantly more healthy patients reported respiratory effects $(P=0.032)$ at $8 \mathrm{~h}$ post-discharge, specifically snoring in the car ride home and usually snoring in general; there was no difference between the two groups at $24 \mathrm{~h}$ post-discharge for this category. At 3 months post-surgery, significantly more ASD patients reported GI disturbance $(P=0.008)$ and unusual occurrences $(P=0.013)$ in which they behaved in a way that concerned parents/caregivers. There were no significant differences in CNS effects, level of activity, or sleep disturbance in any of the surveys. However, there was a trend in the 24-h survey showing more ASD patients with difficulty waking up and complaints of bad dreams $(P=0.062)$.

The paired $t$-test was used to determine any significant difference between the specific adverse effect at $8 \mathrm{~h}$ vs. $24 \mathrm{~h}$ after discharge (Table 3). The Pearson correlation test demonstrated that significant correlation between particular categories of adverse behavioral effect (Table 4). All pairs of adverse effects listed in Table 4 had a positive correlation.

There was a slightly higher incidence of neurological problems with Ketorolac use during surgery $(P=0.054)$. There was a significantly higher incidence of behavior that concerned parents/caregivers $(P=0.031)$ and a slightly higher incidence of GI discomfort $(P=0.051)$ with Demerol use. Versed use had significantly higher incidence of psychological problems $(P=0.016)$ and changes in medications after surgery $(P$ $=0.043)$. Atropine use had significantly higher incidence of psychological problems $(P=0.025)$. Remifentanil use had significantly higher incidence of GI discomfort $(P=0.008)$ and changes in medications after surgery $(P=0.003)$. Benadryl use was significantly higher with no changes in medications after surgery $(P=0.039)$.

The ASD group had a larger age range: 11 were younger than 6 years, 18 were 6 years to $<12$ years, and eight were 12 years and older. Significantly higher doses of ketamine $(P=0.048)$, ketorolac $(P=0.021)$, and versed $(P=0.021)$ were used in the 6 to $<12$-years group. Significantly more patients in this group reported that they usually snored $(P=0.023)$. In the 8 -h survey, there were significantly fewer patients in the 6 to $<12$-years group that normally slept in the car $(P=0.003)$ and had GI discomfort $(P=0.044)$. Significantly more patients in this group had CNS effects during this time period. In the 24 -h survey, significantly fewer patients in the 6 to $<12$-years group cried or screamed inconsolably $(P=0.022)$ and had a memory about the dental surgery $(P=0.047)$; significantly more of these patients snored $(P=0.047)$. In the 3 -months survey, significantly fewer patients in the 6 to $<12$-years group reported hyperactivity $(P=0.005)$. There were no significant differences in any age group for any other category.

\section{DISCUSSION}

The results of this study confirmed the statistics of children with ASD previously reported in the literature [15]. Specifically there were significantly more males and higher BMI in the ASD group. Significantly fewer ASD patients did not speak age-appropriately, which was expected because the inclusion criteria for the ASD group in this study was that the patient must have deficiencies in nonverbal and verbal communication skills. This group also 
TABLE 2 | Survey questions comparing incidence of adverse behavioral events after GA.

Yes $N(\%) \quad$ Healthy $N(\%) \quad$ ASD $N(\%) \quad P$-value chi-square

\section{Survey 1: Initial survey}

Prior to GA induction, did the patient:

1P. Cry or scream inconsolably?

2P. Exhibit any aggressive behavior?

3P. Bite or scratch anyone?

4P. Seem hyperactive?

5. Speak age-appropriately?

6. Walk on their own, if age appropriate?

7. Does your child snore?

During GA surgery, did the patient:

$8 \mathrm{~A}$. Require the use of reversal agents?

9A. Saturation level ever drop below 90\%?

10A. Require head repositioning? (> five times per hour)

11A. Have any abnormal rash?

12A. At any point was treatment aborted? (if yes, why?)

At discharge, could the patient:

13. Sit unaided?

14. Hold their head up on their own?

15. Speak age-appropriately?

Survey 2: 8-H GA follow-up phone survey

After leaving the surgery clinic, did your child:

1P. Cry or scream inconsolably?

2P. Exhibit any abnormally aggressive behavior?

3P. Bite or scratch anyone?

4P. Seem hyperactive?

5S. Fall asleep on the car ride home?

5a. Does your child normally sleep in the car?

$5 \mathrm{bR}$. Did your child snore?

5c. Does your child usually snore?

$5 \mathrm{dS}$. Was it difficult to awaken your child when you arrived home?

$6 \mathrm{U}$. Act in a way that made you concerned and caused you to pull the car over?

7S. Sleep soon after arriving home?

7aS. Did your child complain of bad dreams?

8L. Need help to sit up?

9L. Have difficulty walking?

10L. Seem lethargic?

$11 \mathrm{~L}$. Play immediately after arriving home?

12C. Talk less than normal or refuse to talk?

13C. Talk more than normal?

14C. Slur or speak incoherently?

15C. Complain of or seem dizzy?

16. Have any memory of what happened at the surgery clinic?

17. Talk about the dental surgery?

18C. Have or complain of a headache?

19G. Complain of nausea?

20G. Vomit?

21G. Have an upset stomach?

22G. Have diarrhea?

23U. Take any medication?

24U. Have any abnormal rash?

\begin{tabular}{|c|c|c|c|}
\hline $8(10.4)$ & $3(7.5)$ & 5 (13.5) & 0.388 \\
\hline $7(9.1)$ & $0(0)$ & 7 (18.9) & $0.004^{*}$ \\
\hline $2(2.6)$ & $0(0)$ & $2(5.4)$ & 0.136 \\
\hline 8 (10.4) & $2(5.0)$ & 5 (13.5) & 0.107 \\
\hline $43(55.8)$ & 38 (95.0) & 5 (13.5) & $<0.001^{*}$ \\
\hline 76 (98.7) & 39 (97.5) & 37 (100) & 0.333 \\
\hline $21(27.3)$ & 13 (32.5) & 7 (18.9) & 0.113 \\
\hline $4(5.2)$ & $1(2.5)$ & $3(8.1)$ & 0.268 \\
\hline $1(1.3)$ & $0(0)$ & $1(2.7)$ & 0.295 \\
\hline $0(0)$ & $0(0)$ & $0(0)$ & $\mathrm{N} / \mathrm{A}$ \\
\hline $0(0)$ & $0(0)$ & $0(0)$ & $\mathrm{N} / \mathrm{A}$ \\
\hline $0(0)$ & $0(0)$ & $0(0)$ & N/A \\
\hline 77 (100) & $40(100)$ & 37 (100) & $\mathrm{N} / \mathrm{A}$ \\
\hline 77 (100) & 40 (100) & 37 (100) & $\mathrm{N} / \mathrm{A}$ \\
\hline $43(55.8)$ & 38 (95.0) & 5 (13.5) & $<0.001^{*}$ \\
\hline 12 (15.6) & $8(20.0)$ & $4(10.8)$ & 0.267 \\
\hline $4(5.2)$ & $4(10.0)$ & $0(0)$ & 0.048 \\
\hline $1(1.3)$ & $0(0)$ & $1(2.7)$ & 0.295 \\
\hline $7(9.1)$ & $4(10.0)$ & $3(8.1)$ & 0.773 \\
\hline $66(85.7)$ & 37 (92.5) & $29(7.8)$ & 0.077 \\
\hline $36(46.8)$ & $26(65.0)$ & $10(27.0)$ & $0.001^{*}$ \\
\hline 21 (27.3) & 15 (37.5) & $6(16.2)$ & $0.036^{\star}$ \\
\hline $19(24.7)$ & 13 (32.5) & $6(16.2)$ & 0.098 \\
\hline $11(14.3)$ & $4(10.0)$ & 7 (18.9) & 0.264 \\
\hline $2(2.6)$ & $1(2.5)$ & $1(2.7)$ & 0.955 \\
\hline 48 (62.3) & $24(60.0)$ & 24 (64.9) & 0.660 \\
\hline 3 (3.9) & $1(2.5)$ & $2(5.4)$ & 0.510 \\
\hline $18(23.4)$ & 7 (17.5) & $11(29.7)$ & 0.205 \\
\hline 27 (35.1) & $9(22.5)$ & 18 (48.6) & $0.016^{*}$ \\
\hline $46(59.7)$ & $26(65.0)$ & $20(54.1)$ & 0.328 \\
\hline $19(24.7)$ & 12 (30.0) & 7 (18.9) & 0.260 \\
\hline 32 (41.6) & 17 (42.5) & $15(40.5)$ & 0.862 \\
\hline $0(0)$ & $0(0)$ & $0(0)$ & $\mathrm{N} / \mathrm{A}$ \\
\hline $5(6.5)$ & $3(7.5)$ & $3(8.1)$ & 0.573 \\
\hline 23 (29.9) & $8(20.0)$ & $15(40.5)$ & 0.070 \\
\hline 26 (33.8) & 14 (35.0) & $12(32.4)$ & 0.101 \\
\hline 32 (41.6) & 19 (47.5) & $13(35.1)$ & $0.027^{*}$ \\
\hline $4(5.2)$ & $1(2.5)$ & $3(8.1)$ & 0.167 \\
\hline $10(13.0)$ & $2(5.0)$ & 8 (21.6) & $0.030 *$ \\
\hline $9(11.7)$ & $3(7.5)$ & $6(16.2)$ & 0.234 \\
\hline $3(3.9)$ & $2(5.0)$ & $1(2.7)$ & 0.603 \\
\hline $1(1.3)$ & $0(0)$ & $1(2.7)$ & 0.295 \\
\hline 33 (42.9) & $18(45.0)$ & $15(40.5)$ & 0.693 \\
\hline $3(3.9)$ & $2(5.0)$ & $1(2.7)$ & 0.603 \\
\hline
\end{tabular}

(Continued) 


\section{Survey 3: 24-H GA follow-up phone survey}

After leaving the surgery clinic, did your child:

1P. Cry or scream inconsolably?

2P. Exhibit any abnormally aggressive behavior?

3P. Bite or scratch anyone?

4P. Seem hyperactive?

5S. Sleep more or less than normal?

$5 \mathrm{aR}$. Did your child snore?

5 b. Does your child usually snore?

$5 c S$. Was it difficult to awaken your child?

$5 d S$. Did your child complain of bad dreams?

6L. Need help to sit up?

7L. Have difficulty walking?

8L. Seem lethargic?

9L. Play more or less than normal?

10C. Talk less than normal or refuse to talk?

11C. Talk more than normal?

12C. Slur or speak incoherently?

13C. Complain of or seem dizzy?

14. Have any memory of what happened at the surgery clinic?

15. Talk about the dental surgery?

16C. Have or complain of a headache?

$17 \mathrm{G}$. Complain of nausea?

18G. Vomit?

19G. Have an upset stomach?

20G. Have diarrhea?

21U. Take any medication?

22U. Have any abnormal rash?

$23 U$. Act in a way that made you concerned?

Survey 4: 3-months GA follow-up phone survey

Since the 24-h follow-up, did your child exhibit any:

1C. Psychological problems (aggressive behavior, crying or screaming, insomnia, nightmares)?

2G. Gastrointestinal problems (nausea, vomiting, diarrhea, constipation, upset stomach, loss of appetite)?

3C. Neurological problems (relapse in behavior, dizziness, or headaches)?

4P. Seem hyperactive?

$5 \mathrm{U}$. Act in a way that made you concerned?

$6 \mathrm{U}$. Any changes in medications after surgery?

\begin{tabular}{|c|c|c|c|}
\hline $5(6.5)$ & $3(7.5)$ & $2(5.4)$ & 0.709 \\
\hline $1(1.3)$ & $1(2.5)$ & $0(0)$ & 0.333 \\
\hline $0(0)$ & $0(0)$ & $0(0)$ & $\mathrm{N} / \mathrm{A}$ \\
\hline $10(13.0)$ & $5(12.5)$ & 5 (13.5) & 0.895 \\
\hline $19(24.7)$ & $9(22.5)$ & $10(27.0)$ & 0.645 \\
\hline $17(22.1)$ & $12(30.0)$ & 5 (13.5) & 0.081 \\
\hline $18(23.4)$ & $12(30.0)$ & $6(16.2)$ & 0.153 \\
\hline $4(5.2)$ & $1(2.5)$ & $3(8.1)$ & 0.303 \\
\hline $2(2.6)$ & $0(0)$ & $2(5.4)$ & 0.185 \\
\hline $2(2.6)$ & $2(5.0)$ & $0(0)$ & 0.168 \\
\hline $3(3.9)$ & $2(5.0)$ & $1(2.7)$ & 0.603 \\
\hline $17(22.1)$ & $9(22.5)$ & 8 (21.6) & 0.926 \\
\hline $16(20.8)$ & $6(15.0)$ & $10(27.0)$ & 0.194 \\
\hline $6(7.8)$ & $2(5.0)$ & $4(10.8)$ & 0.342 \\
\hline $6(7.8)$ & $3(7.5)$ & $3(8.1)$ & 0.921 \\
\hline $3(3.9)$ & $2(5.0)$ & $1(2.7)$ & 0.511 \\
\hline $4(5.2)$ & $3(7.5)$ & $1(2.7)$ & 0.343 \\
\hline $17(22.1)$ & $8(20.0)$ & $9(24.3)$ & 0.078 \\
\hline $25(32.5)$ & 15 (37.5) & $10(27.0)$ & $0.048^{*}$ \\
\hline $1(1.3)$ & $0(0)$ & $1(2.7)$ & 0.185 \\
\hline $0(0)$ & $0(0)$ & $0(0)$ & $\mathrm{N} / \mathrm{A}$ \\
\hline $0(0)$ & $0(0)$ & $0(0)$ & $\mathrm{N} / \mathrm{A}$ \\
\hline $2(2.6)$ & $1(2.5)$ & $1(2.7)$ & 0.955 \\
\hline $1(1.3)$ & $0(0)$ & $1(2.7)$ & 0.295 \\
\hline $29(37.7)$ & $14(35.0)$ & 15 (40.5) & 0.616 \\
\hline $1(1.3)$ & $1(2.5)$ & $0(0)$ & 0.333 \\
\hline $3(3.9)$ & $1(2.5)$ & $2(5.4)$ & 0.510 \\
\hline 8 (10.4) & $2(5.0)$ & $6(16.2)$ & 0.107 \\
\hline 8 (10.4) & $3(7.5)$ & 5 (13.5) & 0.388 \\
\hline 3 (3.9) & $1(2.5)$ & $2(5.4)$ & 0.510 \\
\hline 14 (18.2) & $4(10.0)$ & $10(27.0)$ & 0.053 \\
\hline $6(7.8)$ & $0(0)$ & $6(16.2)$ & $0.008^{*}$ \\
\hline $7(9.1)$ & $2(5.0)$ & 5 (12.5) & 0.194 \\
\hline
\end{tabular}

N, Number of Responders; \%, Frequency, ${ }^{\star} P<0.05$ using chi-square test to indicate differences between Healthy and ASD who answered "Yes." $P$, Paradoxical Reaction; S, Sleep

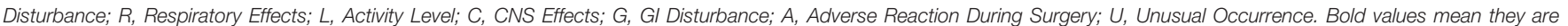
statistically significant.

had a greater tendency to show aggressive behavior at baseline. These types of behavior often render the use of intramuscular Ketamine induction because the patient is unable to cooperate for mask induction, which was demonstrated by the results of this study. The ASD group had a wider age range compared to the healthy group because of the patients available at SCD. When comparing demographics and responses for the three age groups, there were few significant differences most likely due to the fact that the majority of the ASD patients were between age 6 and 12 years.
A greater number of healthy patients reported snoring on the car ride home, which matched their positive response to regularly snoring in general. A larger number of healthy patients also talked about the dental surgery, most likely because the ASD patients had deficiencies in verbal communication. Patients in the ASD group had more nausea and difficulty walking at $8 \mathrm{~h}$ post-discharge, suggesting that this group experienced a stronger effect on GI disturbance and activity level overall. Patients who experienced CNS effects at $8 \mathrm{~h}$ post-discharge generally had higher incidence of CNS effects, sleep disturbances, and low 

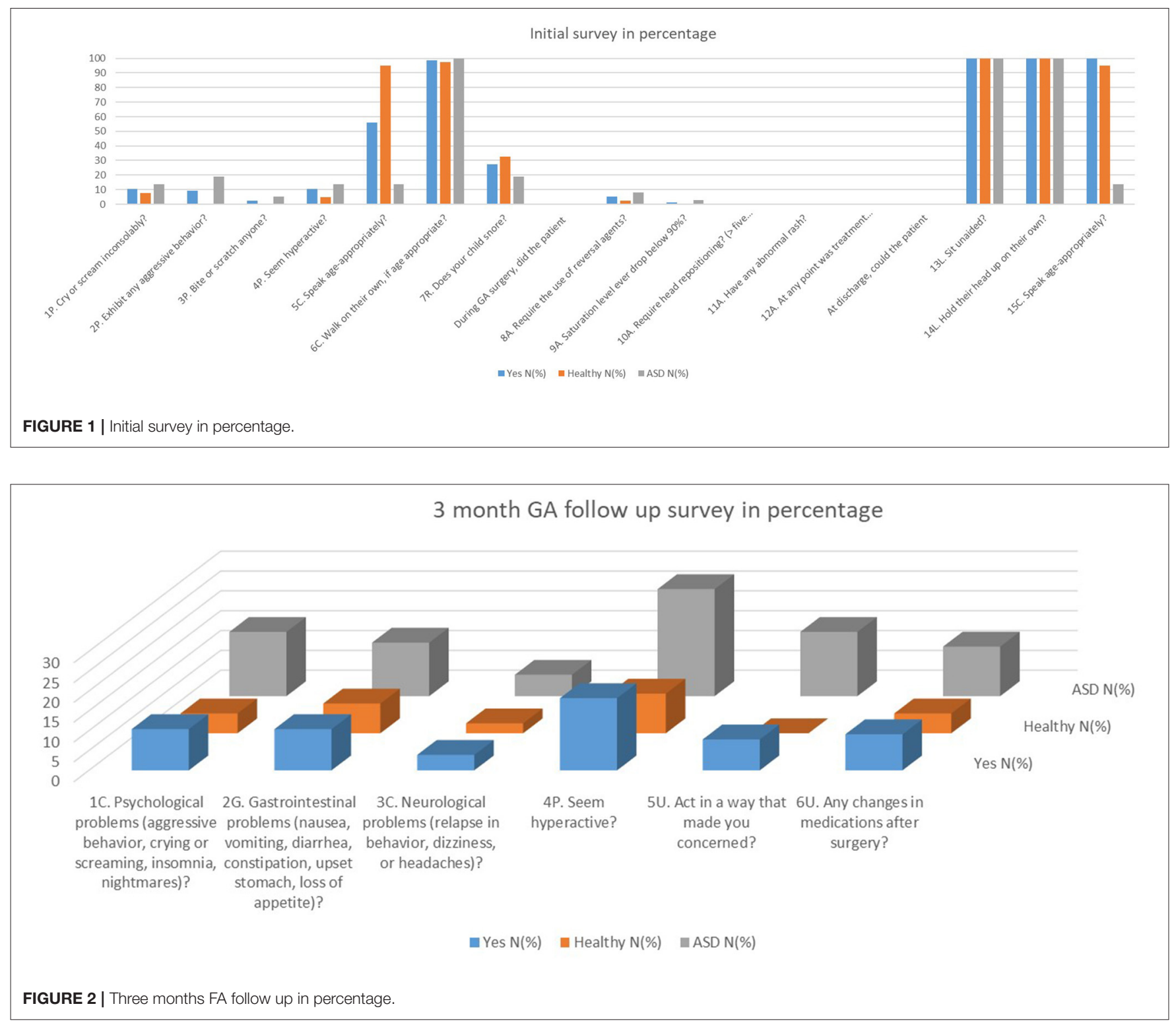

activity level at $24 \mathrm{~h}$ post-discharge. More adverse behavioral effects can be expected at $24 \mathrm{~h}$ if the patient demonstrated CNS problems at $8 \mathrm{~h}$ post-discharge. The fact that adverse behavioral effects occurred at a $6.57 \%$ frequency during the 3 -months survey showed that most of these effects last short term. Overall, most incidence of adverse behavioral effects significantly decreased over time (Table 2).

McCormack et al. concluded that a higher incidence of adverse effects occurred within $8 \mathrm{~h}$ after discharge [1]. In particular, there was increased sleep time, effect on activity level (difficulty walking, talking less than normal after arriving home), and CNS effects (slurring, difficulty speaking) [1]. Similarly, our study found that the greatest incidence of adverse behavioral effects occurred within $8 \mathrm{~h}$ after discharge, and the second highest incidence occurred $24 \mathrm{~h}$ after discharge. Between the 8-h and 24-h surveys in this study, there were significant decreases in sleep disturbance, effects on activity level, CNS effects, and GI discomfort. There were significant decreases in unusual occurrences (abnormal rash, changes in medications, and concerning behavior) between $8 \mathrm{~h}$ and 3 months and between $24 \mathrm{~h}$ and 3 months, suggesting that these effects are not long term (Table 3).

The 3-months follow up survey served to study the longterm effects of GA (Figure 2). Patients with aggressive behavior and hyperactivity at baseline tended to have higher incidence of adverse reactions during surgery, GI disturbances $8 \mathrm{~h}$ postdischarge, sleep disturbance $24 \mathrm{~h}$ post-discharge, and CNS effects 3 months post-discharge. This 3-months survey revealed that significantly more ASD patients acted in a way that concerned their parents/caregivers. One parent reported that the patient had a calmer and less active behavior with delayed response to commands. Several parents reported insomnia, random 
TABLE 3 | Paired $t$-test statistics for adverse behavioral effects over time.

\begin{tabular}{|c|c|c|c|c|}
\hline Survey questions & Mean & $\begin{array}{l}\text { Standard } \\
\text { deviation }\end{array}$ & $\begin{array}{l}\text { Standard } \\
\text { error }\end{array}$ & Significance \\
\hline Paradoxical reaction $8 \mathrm{~h}$ & 0.31 & 0.59 & 0.07 & $P=0.219$ \\
\hline Paradoxical reaction $24 \mathrm{~h}$ & 0.21 & 0.5 & 0.06 & Not significant \\
\hline Sleep disturbance $8 \mathrm{~h}$ & 0.17 & 0.45 & 0.05 & $P=0.034^{*}$ \\
\hline Sleep disturbance $24 \mathrm{~h}$ & 0.08 & 0.27 & 0.03 & $\begin{array}{l}\text { Significant } \\
\text { decrease }\end{array}$ \\
\hline Level of activity $8 \mathrm{~h}$ & 1.43 & 0.98 & 0.11 & $P<0.001^{*}$ \\
\hline Level of activity $24 \mathrm{~h}$ & 0.49 & 0.9 & 0.1 & $\begin{array}{l}\text { Significant } \\
\text { decrease }\end{array}$ \\
\hline CNS effects $8 \mathrm{~h}$ & 1.71 & 1.24 & 0.15 & $P<0.001^{*}$ \\
\hline CNS effects $24 \mathrm{~h}$ & 0.87 & 0.97 & 0.12 & $\begin{array}{l}\text { Significant } \\
\text { decrease }\end{array}$ \\
\hline Gl discomfort $8 \mathrm{~h}$ & 0.3 & 0.62 & 0.07 & $P=0.001^{*}$ \\
\hline Gl discomfort $24 \mathrm{~h}$ & 0.04 & 0.25 & 0.03 & $\begin{array}{l}\text { Significant } \\
\text { decrease }\end{array}$ \\
\hline Respiratory effects $8 \mathrm{~h}$ & 0.52 & 0.77 & 0.09 & $P=0.228$ \\
\hline Respiratory effects $24 \mathrm{~h}$ & 0.45 & 0.79 & 0.09 & Not significant \\
\hline Unusual occurrence $8 \mathrm{~h}$ & 0.45 & 0.53 & 0.06 & $P=0.581$ \\
\hline Unusual occurrence $24 \mathrm{~h}$ & 0.42 & 0.57 & 0.06 & Not significant \\
\hline Unusual occurrence $24 \mathrm{~h}$ & 0.41 & 0.57 & 0.06 & $P=0.001^{*}$ \\
\hline Unusual occurrence 3 months & 0.17 & 0.44 & 0.05 & $\begin{array}{l}\text { Significant } \\
\text { decrease }\end{array}$ \\
\hline Unusual occurrence $8 \mathrm{~h}$ & 0.45 & 0.52 & 0.06 & $P<0.001^{*}$ \\
\hline Unusual occurrence 3 months & 0.17 & 0.44 & 0.05 & $\begin{array}{l}\text { Significant } \\
\text { decrease }\end{array}$ \\
\hline
\end{tabular}

$N=77$ patients. ${ }^{*} P<0.05$ using paired $t$-test to indicate significant change in incidence of effects between time points. Reported are significant decreases from earlier time point to later time point. Bold values mean they are statistically significant.

screaming, and more aggressive behavior. One patient was irritated more easily for the first month after surgery, but returned to their usual behavior the following month. Another patient in this group was newly diagnosed with ADHD. Previous studies suggested that certain general anesthetics may cause neurodegeneration of the brain, which may lead to ADHD and autism [7]. However, the patient in this study could have already been in the process of being diagnosed for ADHD. As Matton et al. reported, the GA could have caused oxidative stress on the brain [3]. This stress could contribute to post-surgery behavioral changes, including irritability, insomnia, and decreased social engagement, all of which were reported during the 3-months survey [3].

Each drug used during surgery was compared to responses in the 3-months survey to determine any potential long-term effects. Based on our study, the incidence of psychological problems, such as aggressive behavior, screaming, and crying may be associated with the use of Versed and Atropine during surgery. GI discomfort may be associated with Remifentanil and Decadron. Changes in medications after surgery may be associated with the use of Remifentanil and Versed, whereas Benadryl was associated with no changes in medications. Demerol is important to note because its use during surgery correlated with behavior that concerned parents and caregivers.
TABLE 4 | Correlation between adverse behavioral effect type.

\begin{tabular}{|c|c|}
\hline Adverse effect & Correlated with $(r, P$-value $)$ \\
\hline CNS at $8 \mathrm{~h}$ & $\begin{array}{l}\text { Paradoxical at } 24 \mathrm{~h}(\mathrm{r}=+0.290, P=0.015) \\
\mathrm{CNS} \text { at } 24 \mathrm{~h}(\mathrm{r}=+0.512, P<0.001) \\
\text { Sleep at } 8 \mathrm{~h}(\mathrm{r}=+0.290, P=0.016) \\
\text { Sleep at } 24 \mathrm{~h}(\mathrm{r}=+0.491, P<0.001) \\
\text { Activity level at } 8 \mathrm{~h}(\mathrm{r}=+0.570, P<0.001) \\
\text { Activity level at } 24 \mathrm{~h}(\mathrm{r}=+0.510, P<0.001) \\
\text { Gl discomfort at } 8 \mathrm{~h}(\mathrm{r}=+0.433, P<0.001) \\
\text { Unusual occurrence at } 8 \mathrm{~h}(\mathrm{r}=+0.281, P=0.017) \\
\text { Unusual occurrence at } 3 \text { months }(\mathrm{r}=+0.278, P=0.021)\end{array}$ \\
\hline $\mathrm{CNS}$ at $24 \mathrm{~h}$ & $\begin{array}{l}\text { Paradoxical reaction at } 24 \mathrm{~h}(\mathrm{r}=+0.336, P=0.004) \\
\text { Sleep disturbance at } 8 \mathrm{~h}(\mathrm{r}=+0.358, P=0.002) \\
\text { Sleep disturbance at } 24 \mathrm{~h}(\mathrm{r}=+0.363, P=0.002) \\
\text { Activity level at } 24 \mathrm{~h}(\mathrm{r}=+0.426, P<0.001) \\
\text { Unusual occurrence at } 8 \mathrm{~h}(\mathrm{r}=+0.275, P=0.021) \\
\text { Unusual occurrence at } 24 \mathrm{~h}(\mathrm{r}=+0.305, P=0.010) \\
\text { Unusual occurrence at } 3 \text { months }(r=+0.451, P<0.001)\end{array}$ \\
\hline CNS at 3 months & $\begin{array}{l}\text { Paradoxical reaction at } 8 \mathrm{~h}(r=+0.246, P=0.031) \\
\text { Paradoxical reaction at } 24 \mathrm{~h}(r=+0.254, P=0.026) \\
\text { Unusual occurrence at } 3 \text { months }(r=+0.395, P<0.001)\end{array}$ \\
\hline $\begin{array}{l}\text { Gl discomfort } \\
\text { at } 8 \mathrm{~h}\end{array}$ & $\begin{array}{l}\text { Pre-op behavioral issue }(r=+0.346, P=0.002) \\
\text { Sleep disturbance at } 24 \mathrm{~h}(r=+0.271, P=0.010) \\
\text { Activity level at } 8 \mathrm{~h}(r=+0.259, P=0.023) \\
\text { Activity level at } 24 \mathrm{~h}(r=+0.411, P<0.001)\end{array}$ \\
\hline $\begin{array}{l}\text { Unusual occurrence } \\
\text { at } 24 \mathrm{~h}\end{array}$ & $\begin{array}{l}\text { Sleep disturbance at } 24 \mathrm{~h}(\mathrm{r}=+0.439, P<0.001) \\
\text { Gl discomfort at } 24 \mathrm{~h}(\mathrm{r}=+0.246, P=0.031) \\
\text { Unusual occurrence at } 8 \mathrm{~h}(\mathrm{r}=+0.404, P<0.001) \\
\text { Unusual occurrence at } 24 \mathrm{~h}(\mathrm{r}=+0.231, P=0.043)\end{array}$ \\
\hline $\begin{array}{l}\text { Sleep disturbance } \\
\text { at } 24 \mathrm{~h}\end{array}$ & $\begin{array}{l}\text { Pre-op behavioral issue }(r=+0.294, P=0.010) \\
\text { Paradoxical reaction at } 24 \mathrm{~h}(r=+0.281, P=0.015) \\
\text { Activity level at } 8 \mathrm{~h}(r=+0.272, P=0.018)\end{array}$ \\
\hline $\begin{array}{l}\text { Respiratory effect } \\
\text { at } 8 \mathrm{~h}\end{array}$ & Respiratory effect at $24 \mathrm{~h}(\mathrm{r}=+0.518, P<0.001)$ \\
\hline Activity level at $8 \mathrm{~h}$ & Activity level at $24 \mathrm{~h}(\mathrm{r}=+0.295, P=0.009)$ \\
\hline
\end{tabular}

Significance set at $P<0.05$. Listed are the significant correlation between specific type of adverse behavioral effect.

Providers should be cautious with the long-term effects of these drugs during GA.

Although these findings shed light on the potential adverse behavioral effects of GA, this study is not without its limitations. The parent/caregiver's interpretation of the survey question may have biased their answer. More specifically, parents of the patients with ASD had difficulty answering certain questions because their child was nonverbal. Depending on how the investigators presented the question, the parent may have responded differently. There were different dental anesthesiologists providing the GA for this study. Although they all followed the guidelines set by the ADA and AAPD, each had their own combination of drugs they preferred to use. Such varying combination of drugs may have affected the outcomes of this study. The long-term follow up survey had a natural limitation. Responses may have been inaccurate as it could be difficult to remember behavior over a long period of time. Future research should reduce confounding factors, perhaps by reducing the patient age range or by creating more specific questions that would be easier to respond for nonverbal patients. Finally, the follow up time could be extended to 6 months post-discharge. 


\section{CONCLUSION}

Based on the results of this study, the following conclusions can be made:

1. Most adverse behavioral effects (i.e., aggressive behavior, crying, screaming, insomnia, nightmares) occurred at 8 and $24 \mathrm{~h}$ after GA.

2. There were significantly more adverse post-GA complications in moderate to severe ASD patients compared to healthy patients, especially at 8 -h post-surgery.

3. At the 3-months follow up survey, significantly more ASD children behaved in a way that concerned their parents, mainly with reports of increased aggressive behavior, irritation, and screaming.

4. Significantly more ASD children received IM ketamine induction for GA.

5. Certain drugs used during GA surgery may have long-term effects. Versed and Atropine were associated with behavioral problems effects (i.e., aggressive behavior, crying, screaming, insomnia, nightmares), Remifentanil and Decadron with GI disturbances, and Demerol with occurrence of behavior that concerned parents.

\section{REFERENCES}

1. McCormack L, Chen J-W, Trapp L, Job A. A comparison of sedation-related events for two multiagent oral sedation regimens in pediatric dental patients. Pediatr Dent. (2014);36:302-8.

2. Ritwik P, Cao LT, Curran R, Musselman RJ. Post-sedation events in children sedated for dental care. Anesth Prog. (2013) 60:54-9. doi: 10.2344/0003-3006-60.2.54

3. Matton S, Romeo GP. Behavioral regression in 2 patients with autism spectrum disorder and attention-deficit/hyperactivity disorder after oral surgery performed with a general anesthetic. J Am Dent Assoc. (2017) 148:51924. doi: 10.1016/j.adaj.2017.05.006

4. Becker DE. Adverse drug reactions in dental practice. Anesth Prog. (2014) 61:26-34. doi: 10.2344/0003-3006-61.1.26

5. Bakri MH, Ismail EA, Ali MS, Elsedfy GO, Sayed TA, Ibrahim A. Behavioral and emotional effects of repeated general anesthesia in young children. Saudi J Anaesth. (2015) 9:161-66. doi: 10.4103/1658-354X.152843

6. DiMaggio C, Sun L, Li G. Early childhood exposure to anesthesia and risk of developmental and behavioral disorders in a sibling birth cohort. Anesth Analg. (2011) 113:1143-51. doi: 10.1213/ANE.0b013e3182147f42

7. Sprung J, Flick RP, Katusic SK, Colligan RC, Barbaresi WJ, Bojanić $\mathrm{K}$, et al. Attention-deficit/hyperactivity disorder after early exposure to procedures requiring general anesthesia. Mayo Clin Proc. (2012) 87:120-9. doi: 10.1016/j.mayocp.2011.11.008

8. Brambrink AM, Evers AS, Avidan MS, Farber NB, Smith DJ, Zhang $\mathrm{X}$, et al. Isoflurane-induced neuroapoptosis in the neonatal rhesus macaque brain. Anesthesiology. (2010) 112:834-41. doi: 10.1097/ALN. 0b013e3181d049cd

9. Creeley C, Dikranian K, Dissen G, Martin L, Olney J, Brambrink A. Propofol-induced apoptosis of neurones and oligodendrocytes in fetal and neonatal rhesus macaque brain. Br J Anaesth. (2013) 110 (Suppl. 1):i29-i38. doi: $10.1093 /$ bja/aet173

10. Jevtovic-Todorovic V. Pediatric anesthesia neurotoxicity: an overview of the 2011 SmartTots panel. Anesth Analg. (2011) 113:965-8. doi: 10.1213/ANE.0b013e3182326622

11. Loepke AW, Soriano SG. An assessment of the effects of general anesthetics on developing brain structure and neurocognitive function. Anesth Analg. (2008) 106:1681-707. doi: 10.1213/ane.0b013e318167ad77

12. Slikker W Jr, Zou X, Hotchkiss CE, Divine RL, Sadovova N, Twaddle NC, et al. Ketamine-induced neuronal cell death in the perinatal rhesus monkey. Toxicol Sci. (2007) 98:145-58. doi: 10.1093/toxsci/kfm084

\section{DATA AVAILABILITY STATEMENT}

The original contributions presented in the study are included in the article/supplementary material, further inquiries can be directed to the corresponding author/s.

\section{AUTHOR CONTRIBUTIONS}

JT collected data and drafted the manuscript. J-WC designed the study, supervised data collection, analyzed data, and reviewed the manuscript. LT supervised data collection and reviewed the manuscript. LM designed the survey and edited the manuscript. All authors contributed to the article and approved the submitted version.

\section{FUNDING}

The authors wish to thank the Center for Dental Research at Loma Linda University for funding the research project.

13. Orser BA, Suresh S, Evers AS. SmartTots update regarding anesthetic neurotoxicity in the developing brain. Anesth Analg. (2018) 126:1393-6. doi: 10.1213/ANE.0000000000002833

14. Sun LS, Li G, DiMaggio C, Byrne M, Rauh V, Brooks-Gunn J, et al. Anesthesia and neurodevelopment in children: time for an answer? Anesthesiology. (2008) 109:757-61. doi: 10.1097/ALN.0b013e31818a37fd

15. McDonald RE, Avery DR, Dean JA. Pharmacologic management of patient behavior. In: Dean JA, Avery DR, McDonald RE, editors. McDonald and Avery's Dentistry for the Child and Adolescent. 9th ed. Maryland Heights, Mo.: Mosby Elsevier (2011). p. 1-18. doi: 10.1016/B978-0-323-05724-0.50005-9

16. Camm JH, Mourino A, Cobb E, Doyle T. Behavioral changes of children undergoing dental treatment using sedation vs. general anesthesia. Pediatr Dent. (1987) 9:111-7.

17. Autism Speaks. DSM-5 Criteria. Available online at: https://www. autismspeaks.org/dsm-5-criteria (accessed July 17, 2018).

18. Coté CJ, Wilson S. Guidelines for monitoring and management of pediatric patients during and after sedation for diagnostic and therapeutic procedures: an update. Pediatr Dent. (2016) 38:13-39. doi: 10.1542/peds.2016-1212

19. American Dental Association. Guidelines for the Use of Sedation and General Anesthesia by Dentists. Available online at: www.ada.org/sectiona/about/pdfs/anesthesia)guidelines.pdf (accessed June 10, 2019).

Conflict of Interest: The authors declare that the research was conducted in the absence of any commercial or financial relationships that could be construed as a potential conflict of interest.

Publisher's Note: All claims expressed in this article are solely those of the authors and do not necessarily represent those of their affiliated organizations, or those of the publisher, the editors and the reviewers. Any product that may be evaluated in this article, or claim that may be made by its manufacturer, is not guaranteed or endorsed by the publisher.

Copyright (c) 2021 Tran, Chen, Trapp and McCormack. This is an open-access article distributed under the terms of the Creative Commons Attribution License (CC BY). The use, distribution or reproduction in other forums is permitted, provided the original author(s) and the copyright owner(s) are credited and that the original publication in this journal is cited, in accordance with accepted academic practice. No use, distribution or reproduction is permitted which does not comply with these terms. 